\title{
KAPASITAS ASIMILASI PERAIRAN PESISIR KABUPATEN SIDOARJO TERHADAP PRODUKTIFITAS BUDIDAYA UDANG DAMPAK PEMBUANGAN LUMPUR LAPINDO
}

\author{
Oleh \\ Dinno Sudinno \\ Dosen Sekolah Tinggi Perikanan Jurusan Penyuluhan Perikanan
}

\begin{abstract}
Abstrak
Pembuangan Lumpur Lapindo melalui Kali Porong akan berdampak pada ancaman kelangsungan usaha perikanan budidaya tambak udang. Dengan menggunakan pendekatan kesesuaian kualitas air serta kaidah budidaya yang berkelanjutan yang diberikan oleh berbagai pakar. Hasil studi menunjukkan bahwa beban pencemar TSS yang masuk ke perairan pantai Sidoarjo sebesar 5154 Ton/Hari sedangkan kapasitas asimilasi sebesar 2705 ton per hari. Hal ini menunjukkan bahwa perairan pantai Sidoarjo telah tercemar oleh bahan pencemar TSS. Secara kualitatif perairan Sidoarjo mempunyai nilai indeks Diversitas plankton secara keseluruhan tergolong sangat rendah yakni dari $\mathbf{0 , 2 4 8 8}$ sampai $\mathbf{0 , 7 3 7 4}$. berdasarkan hubungan konsentrasi TSS terhadap Kelimpahan plankton, produksi udang diperkirakan mengalami penurunan dari 3515 ton menjadi 3361,3 ton atau sebanyak 153,8 ton .
\end{abstract}

Kata Kunci : Kapasitas Asimilasi, Lumpur

\section{PENDAHULUAN}

Pesisir Kabupaten Sidoarjo merupakan wilayah pesisir yang memiliki lahan tambak sangat luas, dan sebagai kawasan pertambakan udang organik. Selama ini kawasan tambak tersebut dipelihara komoditi udang windu, bandeng dan rumput laut.

Pembuangan Lumpur ke laut melalui sungai Porong akan berdampak terhadap lingkungan pesisir dan laut di sepanjang selat Madura dan sebagian laut Jawa. Air lumpur yang mengandung TSS yang tinggi melebihi baku mutu dapat mempengaruhi lingkungan tambak antara lain kualitas air, sedimen, pakan alami dan produktifitas tambak. Berdasarkan hal tersebut, maka diperlukan analisa produktifitas budidaya tambak udang pada kawasan pesisir kabupaten Sidoarjo sebagai dampak dari pembuangan lumpur Lapindo.

Tujuan penelitian ini adalah untuk Mengetahui beban pencemar TSS dan kapasitas asimilasinya serta mengetahui produktifitas tambak udang di pesisir kabupaten Sidoarjo

\section{METODE PENELITIAN}

Penelitian dilakukan di kabupaten Sidoarjo yang merupakan salah satu pusat kegiatan budidaya tambak udang organik, metode yang digunakan dalam penelitian ini adalah metode survey. Survey dilakukan pada 3 (tiga) stasiun muara sungai, 3 (tiga) stasiun di laut dan 5 stasiun lokasi tambak.

Data yang digunakan dalam penelitian ini adalah data primer dan data sekunder. 
- Data primer adalah data yang diperoleh melalui survei langsung di lapangan yaitu:

1) Parameter TSS

2) Parameter Biologi (Fitoplankton )

3) Debit Aliran Sungai

- Data sekunder diperoleh melalui kajian terhadap laporan - laporan hasil penelitian, publikasi ilmiah, peraturan perundang-undangan dan publikasi daerah. Data tersebut berasal dari instansi pemerintah maupun swasta yang mempunyai relevansi dengan tujuan penelitian meliputi :

- Data produksi udang tahun 2007 (Dinas kelautan dan perikanan Kabupaten Sidoarjo)

- Hubungan kelimpahan Plankton dengan Klorofil a (Handayani dan Patria 2005)
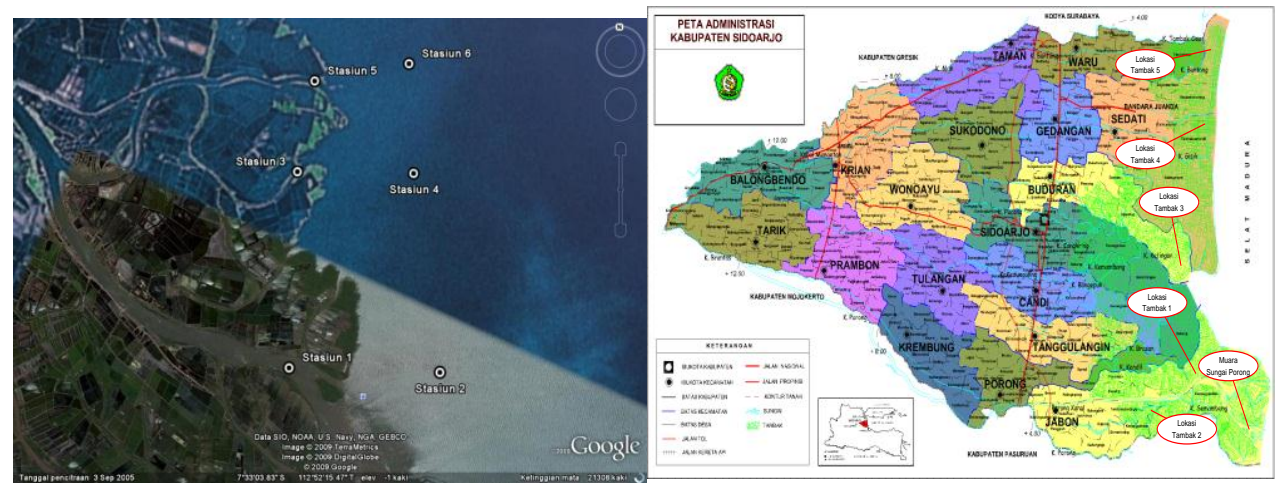

Gambar 1. Lokasi Penelitian

\section{Analisis Data}

\section{Analisis Beban Pencemar TSS}

Penghitungan beban pencemaran ini didasarkan atas pengukuran debit sungai dan konsentrasi limbah di muara sungai berdasarkan persamaan (Mitsch \& Goesselink, 1993)

\section{$B P=Q \times C$}

Keterangan: $\mathrm{BP}=$ beban pencemaran

$\mathrm{Q}=$ debit sungai $\left(\mathrm{m}^{3} /\right.$ detik)

$\mathrm{C}=$ konsentrasi limbah ( $\mathrm{mg} /$ liter)

\section{Analisis Kapasitas Asimilasi}

Untuk menghitung kapasitas asimilasi perairan pantai terhadap beban pencemaran dilakukan dengan menggunakan metode hubungan antara konsentrasi parameter limbah di perairan Pantai dengan beban limbah di muara sungai. Nilai kapasitas asimilasi didapatkan dengan cara membuat grafik hubungan antara nilai konsentrasi masing-masing parameter limbah di perairan pantai dengan parameter limbah tersebut di muara sungai. Selanjutnya dianalisis dengan memotongkan dengan garis nilai baku mutu air

\section{Analisis Produktifitas Tambak Udang}

Untuk pendugaan Produksi udang didasarkan pada :

- Hubungan kelimpahan Plankton dengan klorofil-a

- Hubungan konsentrasi TSS dengan kelimpahan plankton

Selanjutnya nilai klorofil a di konversi menjadi produksi mikroalga yang merupakan konversi laju produksi mikroalga yang dikalikan dengan Ekotropik Efisiensi (EE) untuk mendapatkan jumlah mikroalga yang dikonsumsi oleh predatornya. Pada perhitungan ini asumsi yang digunakan adalah EE bernilai 0,279 . Proses selanjutnya adalah mengalikan hasil perhitungan sebelumnya dengan koefisien 0.007 untuk mengubah biomass mikroalga menjadi biomass udang (Martinez-Goss, 1999) dalam Sapto (2008). 
HASIL DAN PEMBAHASAN

\section{Penghitungan Beban Pencemaran}

Penghitungan beban pencemaran dari parameter TSS dihitung berdasarkan perkalian antara debit sungai dengan konsentrasi TSS yang diteliti. Berdasarkan perhitungan bahwa beban pencemar TSS yang masuk ke perairan pantai sidoarjo sebesar 5154 Ton/Hari.

\section{Pendugaan Kapasitas Asimilasi Perairan}

Penentuan kapasitas asimilasi untuk TSS dilakukan dengan persamaan regresi Kapasitas Asimilasi $=44,84+0,013$ TSS dengan $R^{2}=0,97$. Hasil perpotongan garis regresi dengan garis nilai baku mutu TSS (80 mg/l) menghasilkan nilai kapasitas asimilasi sebesar 2705 ton per hari. Sedangkan beban bahan pencemar TSS yang masuk ke perairan pantai Sidoarjo sebesar 5154 ton/hari Hal ini menunjukkan bahwa perairan pantai sidoarjo telah tercemar oleh bahan pencemar TSS.

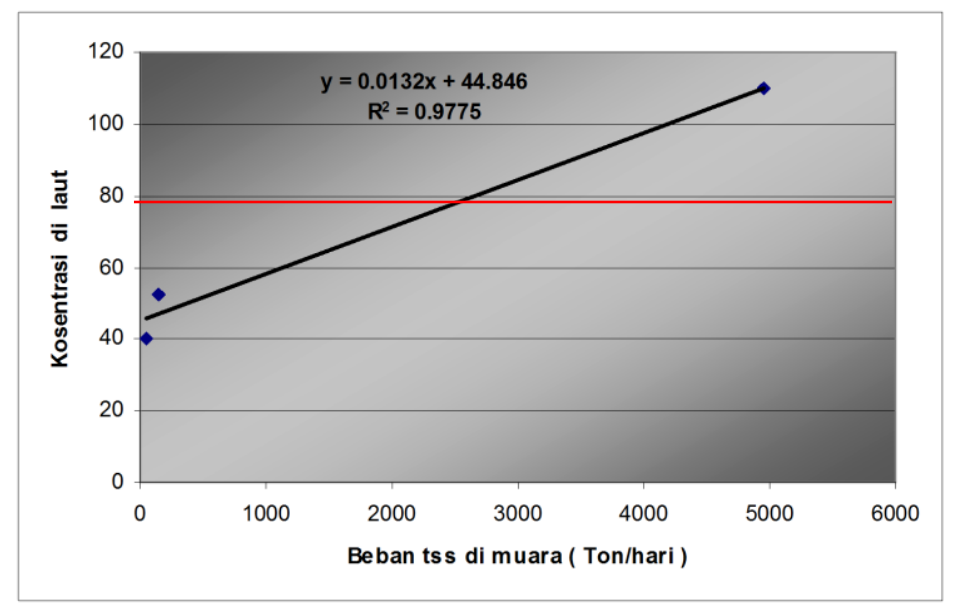

Gambar 2. Kapasitas Asimilasi TSS

Tabel 1. Rangkuman hasil analisis sampel plankton

\begin{tabular}{c|c|c|c|c}
\hline \multicolumn{5}{c}{ Pasang } \\
\hline Stasiun & $\begin{array}{c}\text { Kelimpahan } \\
\text { Total(Sel/Liter) }\end{array}$ & $\begin{array}{c}\text { Jumlah } \\
\text { Taksa }\end{array}$ & $\begin{array}{c}\text { Indeks } \\
\text { Diversitas }\end{array}$ & Tingkat Diversitas \\
\hline Stasiun 1 & 600 & 8 & 0,7374 & Sangat Rendah \\
Stasiun 2 & 1360 & 11 & 0,3983 & Sangat Rendah \\
Stasiun 3 & 1440 & 9 & 0,2743 & Sangat Rendah \\
Stasiun 4 & 1900 & 13 & 0,5765 & Sangat Rendah \\
Stasiun 5 & 1320 & 10 & 0,3509 & Sangat Rendah \\
Stasiun 6 & 1880 & 8 & 0,3696 & Sangat Rendah \\
& & Surut & & Sangat Rendah \\
Stasiun 1 & 400 & 7 & 0,4987 & Sangat Rendah \\
Stasiun 2 & 1040 & 5 & 0,065 & Sangat Rendah \\
Stasiun 3 & 1020 & 7 & 0,2488 & Sangat Rendah \\
Stasiun 4 & 1800 & 10 & 0,3255 & Sangat Rendah \\
Stasiun 5 & 980 & 8 & 0,3578 & Sangat Rendah \\
Stasiun 6 & 1500 & 10 & 0,2958 &
\end{tabular}




\section{Indeks Diversitas Plankton}

Hasil analisis komunitas plankton pada 6 (enam) stasiun pengambilan contoh di perairan pantai sidoarjo mendapatkan data plankton secara keseluruhan berjumlah 13 jenis, terdiri dari 10 jenis fitoplankton dan 3 jenis zooplankton .Pada masing-masing stasiun menunjukkan bahwa jumlah taksa berkisar antara 5 hingga 13 jenis, dengan kelimpahan total berkisar antara 400 hingga 1900 individu/liter. Hasil penghitungan indeks diversitas menunjukkan bahwa tingkat keanekaragaman komunitas plankton secara keseluruhan tergolong sangat rendah yakni dari 0,2488 sampai 0,7374 .

\section{Analisis Produktivitas Tambak Berdasarkan kelimpahan plankton dengan KIorofil}

Pada hubungan kelimpahan plankton terhadap klorofil-a didapatkan persamaan $Y=0,01+0,000262 \quad X$ $\left(R^{2}: 0,79\right)$

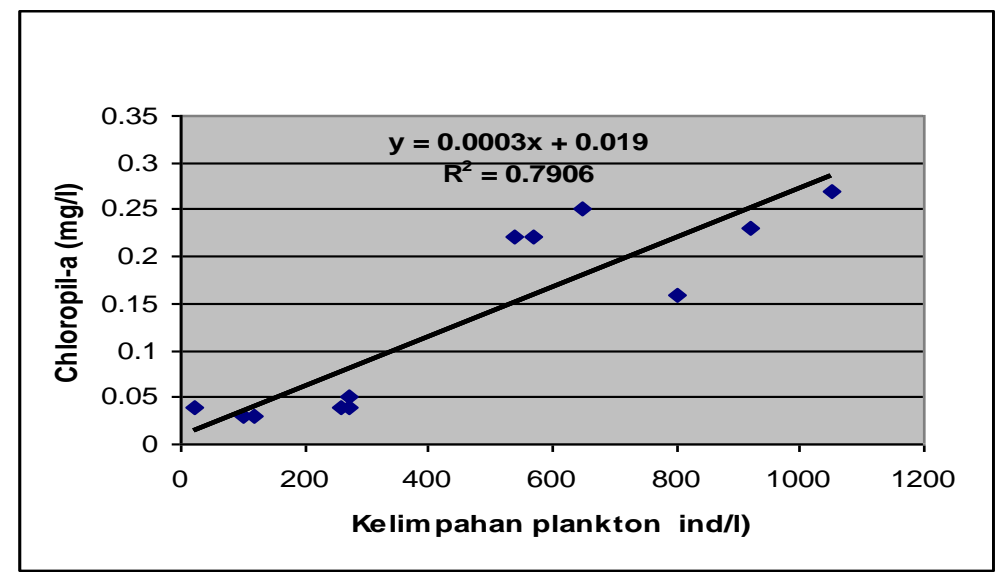

\section{Gambar 3. Hubungan antara Kelimpahan Plankton dengan Klorofil-a (Diolah dari data}

Handayani dan Patria, 2005).

Dari Persamaan 1 data klorofil dapat di hitung. data klorofil selanjutnya di estimasi produktivitas primer mikroalgae. Dari hasil perhitungan didapatkan nilai produktivitas primer mikroalga rata-rata pada pasang adalah 122,85 ton/ha/th dan pada saat surut adalah 98,06 ton/ha/th yang menunjukkan bahwa pada kondisi pasang memiliki potensi produktivitas primer yang lebih tinggi dibandingkan dengan produktivitas rata-rata pada kondisi surut.

Pada kondisi pasang, dengan indek klorofil yang didapatkan pada Tabel 2 dan 3 dengan mengalikan konversi P/B:146,9 dan EE:0,279 maka secara rata-rata didapatkan laju produksi perikanan potensial adalah 0,23990 ton/ha/th. Pada kondisi surut, nilai yang didapatkan relatif lebih kecil dibandingkan pada kondisi pasang, yaitu 0,19148 ton/ha/th. Jika pada kondisi pasang dan surut diambil nilai rata-ratanya, maka secara umum perairan Sidoarjo memiliki laju produksi udang potensial sekitar 0,21569 ton/ha/th. Dari estimasi perhitungan potensi perikanan didapatkan laju perikanan potensial rata-rata sekitar 0,21569 ton/ha/tahun. Dengan luas tambak pada Kabupaten Sidoarjo seluas 15.530 ha maka diperkirakan potensi produksi udang sebesar 3349,6 ton/th. 
Tabel 2. Estimasi Laju Produksi Perikanan Potensial Kondisi Pasang

\begin{tabular}{ccccccc}
\hline No & $\begin{array}{c}\text { Biomass } \\
\text { Mikroalga } \\
\text { (ton/ha.th) }\end{array}$ & $\begin{array}{c}\text { Koefisien } \\
\text { P/B }\end{array}$ & $\begin{array}{c}\text { Produktivitas } \\
\text { Mikroalga } \\
\text { (ton/ha.th) }\end{array}$ & EE & $\begin{array}{c}\text { Mikroalga } \\
\text { yang di } \\
\text { Konsumsi } \\
\text { (ton/ha.th) } \\
\text { E=C x D }\end{array}$ & $\begin{array}{c}\text { Laju Produksi } \\
\text { Perikanan } \\
\text { Potensial } \\
\text { (ton/ha/th } \\
\text { F= E x 0,007 }\end{array}$ \\
\hline 1 & A & B & C= A x B & D & & \\
2 & 0,352152 & 146,9 & 51,7 & 0,279 & 14,42 & 0,10094 \\
3 & 0,792342 & 146,9 & 116,4 & 0,279 & 32,47 & 0,22729 \\
4 & 0,858370 & 146,9 & 126,1 & 0,279 & 35,18 & 0,24626 \\
5 & 1,122484 & 146,9 & 164,9 & 0,279 & 46,01 & 0,32207 \\
6 & 0,792342 & 146,9 & 116,4 & 0,279 & 32,47 & 0,22729 \\
\hline
\end{tabular}

Tabel 3. Estimasi Laju Produksi Perikanan Potensial Kondisi Surut

\begin{tabular}{|c|c|c|c|c|c|c|}
\hline No & $\begin{array}{c}\text { Biomass } \\
\text { Mikroalga } \\
\text { (ton/ha.th) } \\
\text { A }\end{array}$ & $\begin{array}{c}\text { Koefisien } \\
\text { P/B }\end{array}$ & $\begin{array}{l}\text { Produktivitas } \\
\text { Mikroalga } \\
\text { (ton/ha.th) } \\
\text { C= A x B }\end{array}$ & EE & $\begin{array}{l}\text { Mikroalga } \\
\text { yang di } \\
\text { Konsumsi } \\
\text { (ton/ha.th) } \\
\text { E=C x D }\end{array}$ & $\begin{array}{c}\text { Laju Produksi } \\
\text { Perikanan } \\
\text { Potensial } \\
\text { (ton/ha/th } \\
\text { F= E x } 0,007\end{array}$ \\
\hline 1 & 0,242104 & 146,9 & 35,6 & 0,279 & 9,93 & 0,06951 \\
\hline 2 & 0,616266 & 146,9 & 90,5 & 0,279 & 25,24 & 0,17668 \\
\hline 3 & 0,616266 & 146,9 & 90,5 & 0,279 & 25,24 & 0,17668 \\
\hline 4 & 1,056456 & 146,9 & 155,2 & 0,279 & 43,30 & 0,3031 \\
\hline 5 & 0,594256 & 146,9 & 87,3 & 0,279 & 24,35 & 0,17045 \\
\hline 6 & 0,88038 & 146,9 & 129,3 & 0,279 & 36,07 & 0,25249 \\
\hline
\end{tabular}

\section{Konsentrasi TSS di Muara dan Tambak}

Hasil pengukuran TSS di muara sungai Porong Sebesar $250 \mathrm{mg} / \mathrm{l}$, sedangkan pengukuran TSS di tambak kabupaten Sidoarjo dibagi dalam 5 (lima) lokasi yaitu lokasi tambak 1 berjarak $7 \mathrm{~km}$ dari muara sungai Porong (Porong dan Tanggul Angin) sebesar $142 \mathrm{mg} / \mathrm{l}$, lokasi tambak 2 berjarak $9 \mathrm{~km}$ dari muara sungai Porong (Jabon)138 mg/l, lokasi tambak 3 berjarak $14 \mathrm{~km}$ (Sidoarjo, Candi, Buduran) $126 \mathrm{mg} / \mathrm{l}$, lokasi tambak 4 berjarak $17 \mathrm{~km}$ (Sedati) $105 \mathrm{mg} / \mathrm{l}$ dan lokasi tambak 5 berjarak $25 \mathrm{~km}$ (Waru) $67 \mathrm{mg} / \mathrm{l}$.Tingginya nilai TSS di muara ini dapat dimengerti karena sangat dipengaruhi oleh kondisi aliran sungai porong dan sungai kecil lainnya, ketika masuk di petakan tambak kadarnya berkurang, hal ini disebabkan oleh dilakukannya pengendapan di reservoir maupun terperangkap oleh mangrove serta terjadi pengenceran saat pasang.

\section{Analisis Produktifitas tambak Berdasarkan Hubungan Konsentrasi TSS di tambak dengan Kelimpahan Plankton}

Pada hubungan TSS dan kelimpahan plankton, secara rata-rata pada kondisi pasang dan surut didapatkan persamaan $Y=-4,1364 X+1795,7\left(R^{2}: 0,88\right)$ 


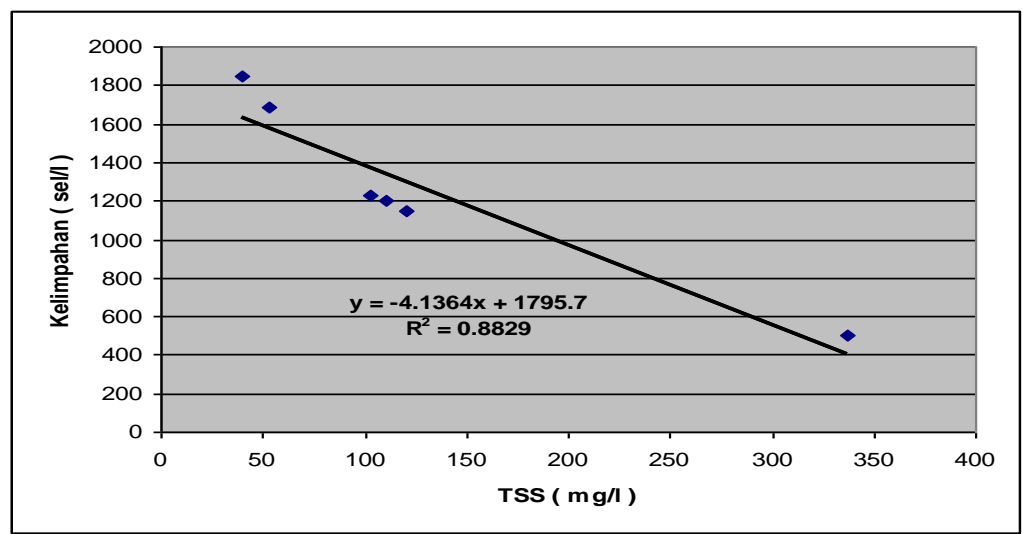

Gambar 4. Hubungan antara TSS Dengan Kelimpahan Plankton (rata-rata pasang surut)

Dari Persamaan 2 dan 1 data klorofil dapat di hitung. Data klorofil selanjutnya di estimasi produktivitas primer mikroalgae. dengan melakukan konversi klorofil-a dengan mengalikan dengan asumsi nilai $\mathrm{P} / \mathrm{B}$ rasio yaitu 146,9 dan Ekotropik Efisiensi 0,279. Seperti terldapat pada Tabel $\mathbf{4}$ dan $\mathbf{5}$.

Tabel 4. Perhitungan Produktivitas Mikroalga

\begin{tabular}{|c|c|c|c|c|c|c|c|c|}
\hline \multirow{2}{*}{$\begin{array}{c}\text { Lokasi } \\
\text { Tambak }\end{array}$} & \multirow{2}{*}{$\begin{array}{l}\text { Nilai } \\
\text { TSS }\end{array}$} & \multirow{2}{*}{$\begin{array}{l}\text { Kelim } \\
\text { pahan } \\
\text { Plankton }\end{array}$} & \multirow{2}{*}{$\begin{array}{l}\text { Kloro } \\
\text { fil-a } \\
(\mathrm{mg} / \mathrm{l})\end{array}$} & \multicolumn{4}{|c|}{ Biomas } & \multirow{2}{*}{$\begin{array}{c}\text { Produksi } \\
\text { Mikro } \\
\text { algae } \\
\text { ton/ha/th }\end{array}$} \\
\hline & & & & $\mu \mathrm{g} / \mathrm{l}$ & $\begin{array}{c}\mathrm{mg} / \\
\mathrm{m} 3\end{array}$ & $\begin{array}{l}\mathbf{g} / \mathbf{m} 2 \\
/ \text { hari }\end{array}$ & $\begin{array}{c}\text { ton/ha } \\
\text { /th }\end{array}$ & \\
\hline LT 1 & 142 & 1208 & 0,32 & 320 & 2,88 & 0,19296 & 0,70430 & 103,4 \\
\hline LT 2 & 138 & 1224 & 0,33 & 330 & 2,97 & 0,19899 & 0,72631 & 106,6 \\
\hline LT 3 & 126 & 1274 & 0,34 & 340 & 3,06 & 0,20502 & 0,74832 & 109,9 \\
\hline LT 4 & 105 & 1361 & 0,36 & 360 & 3,24 & 0,21708 & 0,79234 & 116,3 \\
\hline LT 5 & 67 & 1518 & 0,40 & 400 & 3,60 & 0,2412 & 0,88038 & 129,3 \\
\hline
\end{tabular}

Tabel 5. Estimasi Produksi udang Tahun 2009

\begin{tabular}{ccccccc}
\hline $\begin{array}{c}\text { Produktivitas } \\
\text { Mikroalga } \\
\text { (ton/ha.th) }\end{array}$ & EE & $\begin{array}{c}\text { Mikroalga } \\
\text { yang di } \\
\text { Konsumsi } \\
\text { (ton/ha.th) }\end{array}$ & $\begin{array}{c}\text { Laju } \\
\text { Produksi } \\
\text { Perikanan } \\
\text { Potensial } \\
\text { (ton/ha/th) }\end{array}$ & $\begin{array}{c}\text { Luas lahan } \\
\text { (ha) }\end{array}$ & $\begin{array}{c}\text { Estimasi } \\
\text { Produksi } \\
\text { tahun } \\
\text { 2009 (ton) }\end{array}$ & $\begin{array}{c}\text { Produksi } \\
\text { Tahun } \\
\text { 2007 (ton) } \\
\text { (DKP } \\
\text { Sidoarjo) }\end{array}$ \\
\hline 103,4 & 0,279 & 28,84 & 0,20188 & 993 & 200,4 & 206,3 \\
106,6 & 0,279 & 29,76 & 0,20832 & 4144 & 863,2 & 922,3 \\
109,9 & 0,279 & 30,66 & 0,21462 & 5890 & 1264,1 & 1308,6 \\
116,3 & 0,279 & 32,47 & 0,22729 & 4101 & 932,1 & 972,1 \\
129,3 & 0,279 & 36,07 & 0,25252 & 402 & 101,5 & 105,8 \\
Jumlah & & & & $\mathbf{1 5 . 5 3 0}$ & $\mathbf{3 3 6 1 , 3}$ & $\mathbf{3 5 1 5 , 1}$ \\
\hline
\end{tabular}

Dari estimasi perhitungan potensi perikanan didapatkan laju perikanan potensial lokasi tambak 1 ( Porong dan Tanggul Angin, 993 ha ) sebesar 0,20188 ton/ha/tahun, lokasi tambak 2 (Jabon, 4144 ha) sebesar 0,20832 ton/ha/tahun, lokasi tambak 3 (Candi, Sidoarjo dan Buduran, 5890 ha) sebesar 0,22729 ton/ha/tahun, 
lokasi tambak 4 (Sedati, 4101 ha) sebesar 0,22729 ton/ha/tahun dan lokasi tambak 5 (Waru, 402 ha) sebesar 0,25252 ton/ha/tahun. Dengan luas tambak pada masing-masing lokasi maka diperkirakan potensi produksi udang kabupaten Sidoarjo sebesar 3361,3 ton/th.

Hasil analisis estimasi produksi udang pada tahun 2009 berdasarkan hubungan TSS dan kelimpahan plankton sebesar 3361,3 ton, jumlah ini mengalami penurunan produksi sebesar 153,8 ton dari produksi tahun 2007 yaitu sebesar 3515,1 ton. Berdasarkan hubungan kelimpahan plankton terhadap klorofil-a sebesar 3349,6 ton atau mengalami penurunan sebesar 165,5 ton.

Dari hasil perhitungan diatas, Pembuangan lumpur ke laut melalui Kali Porong, merupakan ancaman tersendiri bagi kawasan tambak di kabupaten Sidoarjo yang dapat berdampak terhadap penurunan produksi dan kegagalan panen usaha budidaya tambak. seperti yang terdapat pada Tabel 6.

Tabel 6. Produksi Udang Kabupaten Sidoarjo tahun 2005-2007

\begin{tabular}{cc}
\hline Tahun & Udang Windu $(\mathbf{k g})$ \\
\hline 2005 & 3.641 .800 \\
2006 & 3.586 .800 \\
2007 & 3.515 .100 \\
\hline
\end{tabular}

Sumber : Dinas Perikanan dan Kelautan Kabupaten Sidoarjo, 2008

Kawasan tambak Kabupaten Sidoarjo yang berpotensi besar terpengaruh adalah kawasan tambak sekitar muara sungai Kali Porong yakni tambak Tegalsari, Pesisiran, Buyuk, Tanjungsari, Pantai, Muara, Tegalan dan kawasan tambak Kanadaan Kecamatan Jabon yang diikuti kawasan tambak Kecamatan Candi dan Sidoarjo Kabupaten Sidoarjo. Luas kawasan pertambakan yang ada digunakan untuk pembudidayaan udang dan bandeng; tetapi sejak munculnya kasus Lapindo ternyata menimbulkan kekhawatiran petambak di Sidoarjo. Di beberapa lokasi terjadi kasus kematian udang sebelum masa panen akibatnya menimbulkan kerugian cukup besar bagi petambak. Kondisi semacam ini bisa disebabkan kualitas air yang kurang baik dan memenuhi persyaratan optimal sebab kebutuhan pengairan tambak masih berasal dari saluran pasang surut yang ada; dan belum memanfaatkan air tanah

September 2006 setelah air lumpur dibuang ke laut melalui Kali Porong, persoalan muncul yakni kematian ikan dan biota air lainnya di sepanjang Kali Porong.
Hasil identifikasi terhadap ikan yang mati lebih disebabkan oleh tersumbatnya insang oleh lumpur dan salinitas air lumpur yang relatif lebih tinggi Pada kasus yang sama luberan air lumpur sempat mempengaruhi sungai Kalidawir dan Penatar Sewu, ikan ditemukan mati secara masal.

Harian Kompas tanggal 22 juni 2009 melaporkan sekitar 300 ha tambak di desa Permisan kecamatan Jabon yang berisi udang mati secara mendadak. Kematian udang ini disebabkan karena pada saat pembudidaya tambak udang melakukan pergantian air jadwalnya bersamaan dengan pembuangan air semburan lumpur lapindo ke sungai Ketapang. Tingkat kekeruhan air pasok ke tambak relatif keruh dan membawa sedimentasi lumpur yang sangat halus, pada tingkat tertentu dapat mematikan ikan Bandeng, udang Windu dan Rumput laut.

Tambak di kabupaten Sidoarjo tergolong tambak tradisional, hal ini dapat dilihat dari pengelolaan air tambak yang hanya tergantung dari pasang surut air laut 
saja, pakan juga masih tergantung dari alam yaitu berdasarkan atas kelimpahan plankton. Pada tambak yang dikelola secara tradisional, udang hanya memakan berbagai jenis pakan alami yang ada didalam tambak, sehingga dengan adanya pembuangan lumpur Lapindo, efek buruk pada ekosistim adalah rendahnya fotosintesa pada tambak yang mempengaruhi tersedianya pakan alami untuk udang. Laju pertumbuhan plankton sangat tergantung pada ketersediaan cahaya di dalam perairan. Partikel lumpur akan menghalangi penetrasi cahaya yang menyebabkan laju pertumbuhan plankton mengalami penurunan. Dengan berkurangnya pakan alami menimbulkan sifat kanibalisme.

Efek lainnya adalah pada tambak yang tidak menggunakan reservoir partikel lumpur akan mengendap di dasar tambak, karena udang hidup didasar perairan dan udang Windu termasuk komoditi perikanan budidaya yang rentan terhadap perubahan kualitas air, sebagian lumpur tersebut akan masuk kedalam insang yang menyebabkan timbulnya penyakit insang hitam yang berujung pada kematian udang. Disamping itu lahan tambak di wilayah Sidoarjo dikenal luas untuk setiap petakannya yakni mencapai 1-5 ha setiap petakan. Kondisi petakan yang demikian tidak dapat dilakukan pengelolaan secara khusus apabila terjadi masalah yang datangnya dari luar atau yang diakibatkan oleh perubahan kualitas air laut yang terbawa air pasang yang kurang menguntungkan.

\section{KESIMPULAN DAN SARAN}

\section{Kesimpulan}

1) Beban pencemar TSS yang masuk ke perairan pantai sidoarjo sebesar 5154 Ton/Hari sedangkan kapasitas asimilasi sebesar 2705 ton per hari.

2) Produksi udang kabupaten Sidoarjo hasil estimasi dengan pendekatan hubungan Kelimpahan plankton terhadap klorofil-a diperkirakan mengalami penurunan produksi sebesar 165,5 ton. Sedangkan berdasarkan hubungan konsentrasi TSS terhadap Kelimpahan plankton diperkirakan mengalami penurunan sebesar 153,8 ton.

\section{Saran}

1) Perlu evaluasi konsentrasi Pembuangan lumpur di Sungai Porong yang akan mengarah ke laut sehingga konsentrasi TSS tidak lebih dari $80 \mathrm{mg} / \mathrm{l}$

2) Dilakukan penyuluhan kepada pembudidaya udang bahwa dalam pengelolaan tambak melakukan treatmen air baik secara fisik, kimia dan biologis sebelum air tersebut dimanfaatkan untuk pemeliharaan. serta jadwal pergantian air tambak waktunya tidak bersamaan dengan pembuangan air lumpur.

\section{DAFTAR PUSTAKA}

Handayani, S, dan Patria M.P. 2005. Komunitas Zooplankton di Perairan Waduk Krenceng Cilegon ,Banten. Makara Sains, Vol. 9 No. 2. November 2005: $75-80$.

Menteri Negara Lingkungan Hidup (2003), Surat Keputusan Menteri Negara Lingkungan Hidup Nomor : 115 Tahun 2003 tentang Pedoman Penentuan Status Mutu Air, Jakarta.

Mitsch, W.J and J.G. Gosselink. 1994. Wetlands. In Water Quality Prevention, Identification and Management of Diffuse Pollution. Van Nostrand Reinhold. New York.

Sapto, A. 2008 Studi Sedimen Melayang dan Dampaknya terhadap Produktivitas Perikanan (Studi Kasus Muara Sungai Porong). ITS. Surabaya. 